\title{
Correction to: Postmortem Diagnosis of Fulminant Type 1 Diabetes Mellitus: Case Report
}

\author{
Tomoyo Takata $^{1,2} \cdot$ Masanobu Miura ${ }^{2} \cdot$ Kaori Taniguchi ${ }^{2} \cdot$ Takashi Kitao $^{1,2} \cdot$ Satoru Miyaishi $^{2}$
}

Published online: 30 April 2021

(C) Springer Nature Switzerland AG 2021

\section{Correction to: SN Comprehensive Clinical Medicine https://doi.org/10.1007/s42399-021-00856-w}

The original article unfortunately contained errors. The address in affiliations 1 and 2 are incorrect. Table 3 has missing close parenthesis in the header and added commas in the data of the last column.

The original article has been corrected.

Publisher's Note Springer Nature remains neutral with regard to jurisdictional claims in published maps and institutional affiliations.

The online version of the original article can be found at https://doi.org/ 10.1007/s42399-021-00921-4

\section{Tomoyo Takata}

takata@epu.ac.jp

1 Department of Medical Technology, Faculty of Health Science, Ehime Prefectural University of Health Sciences, 543 Takoda, Tobe-cho, Iyo-gun, Ehime 791-2101, Japan

2 Department of Legal Medicine, Okayama University Graduate School of Medicine, Dentistry and Pharmaceutical Sciences, 2-5-1, Shikata-cho, Kita-ku, Okayama-shi, Okayama 700-0914, Japan 